\title{
RESORBABLE ELECTROSPUN POLYDIOXANONE FIBRES MODIFY THE BEHAVIOUR OF CELLS FROM BOTH HEALTHY AND DISEASED HUMAN TENDONS
}

\author{
A. Kendal*, S. Snelling, S. Dakin, E. Stace, P-A. Mouthuy and A. Carr \\ Botnar Research Centre, Nuffield Department of Orthopaedics, Rheumatology and Musculoskeletal Sciences, \\ Biomedical Research Unit, Oxford University Institute of Musculoskeletal Sciences, University of Oxford, \\ Oxford, OX3 7LD, UK
}

\begin{abstract}
Chronic tendinopathy in an active and ageing population represents an increasing burden to healthcare systems. Rotator cuff tendinopathy alone accounts for approximately $70 \%$ of all shoulder pain. Tendinopathic tissue has a disorganised extracellular matrix, altered vasculature, and infiltration of fibroblasts and inflammatory cells. This altered biology may contribute to the limited success of surgical repair strategies.

Electrospun resorbable scaffolds can potentially enhance endogenous repair mechanisms by influencing the tissue microenvironment. Polydioxanone (PDO) has an established safety profile in patients. We compared the response of healthy and diseased human tendon cells to electrospun PDO fibres using live cell imaging, proliferation, flow cytometry, and gene expression studies.

Within $4 \mathrm{~h}$ of initial contact with electrospun PDO, healthy tendon cells underwent a marked transformation; elongating along the fibres in a fibre density dependent manner. Diseased tendon cells initially responded at a slower rate, but ultimately underwent a similar morphological change. Electrospun fibres increased the proliferation rate of diseased tendon cells and increased the ratio of type I:III collagen mRNA expression. Flow cytometry revealed decreased expression of CD106, a marker of mesenchymal stem cells, and increased expression of CD10 on healthy versus diseased tendon cells. PDO electrospun scaffolds further promoted CD $106^{\text {neg }} \mathrm{CD} 10^{\text {pos }}$ expression of healthy tendon cells.

Despite their behavioural differences, both healthy and diseased human tendon cells responded to electrospun PDO fibres. This encourages further work establishing their efficacy in augmenting surgical repair of diseased tendons.
\end{abstract}

Keywords: electrospinning, tendinopathy, rotator cuff tendons, live cell imaging, tenocyte.

*Address for correspondence:

Adrian Kendal

Botnar Research Centre,

Nuffield Department of Orthopaedics,

Rheumatology and Musculoskeletal Sciences,

Biomedical Research Unit,

Oxford University Institute of Musculoskeletal Sciences, University of Oxford, Oxford, OX3 7LD, UK

E-mail: adriankendal@hotmail.com

\section{Introduction}

The morbidity associated with tendon disease is an escalating challenge for healthcare systems looking after an active and increasingly ageing population (GBD 2013 DALYs, 2015). Shoulder pain accounts for over $2 \%$ of annual primary care consultations in the UK and up to $70 \%$ of these are due to rotator cuff tendinopathy (Chard et al., 1991; Urwin et al., 1998). Tears of the rotator cuff are painful and debilitating. Conventional surgical repairs using non-degradable sutures and anchors to re-attach the diseased tendon to bone are both costly and associated with failure rates of over $40 \%$ (Bishop et al., 2006; Galatz et al., 2004; Sugaya et al., 2007).

The 'intrinsic' mechanism for tendon degeneration, previously proposed by Codman and Akerson (Codman and Akerson, 1931), is supported by reports of changes in diseased tendon vascularity, extracellular matrix (ECM) composition, cell number, morphology and inflammatory signalling pathways (Dakin et al., 2015; Dean et al., 2012). Similarly, surgical repair is associated with an increase in vascularity, cell proliferation and expression of stress response genes (Dean et al., 2014). Taken together, these findings suggest that resident tendon cells may play a crucial role in maintaining the ECM and responding to external stimuli which disrupt tendon homeostasis.

The growing field of tissue engineering has produced a number of important technological advances in the development of reparative scaffolds. These include 3D printing, hydrogel processing, multilayer fibrous scaffolds, bio-printing and electrospinning of fibres. We have previously demonstrated that electrospun polydioxanone (PDO) fibrous scaffolds encourage the migration and proliferation of primary human tendon cells (Hakimi et al., 2015). PDO has a number of advantageous material properties. It has a well-established safety record as a suture material in patients. It is absorbable which eliminates the long term risk of infection. Fibre diameters in the range of $0.05-5 \mu \mathrm{m}$ can be produced, mimicking the fibrous hierarchy of normal tendon architecture from collagen fibrils $(<500 \mathrm{~nm})$ to primary bundles within a fascicle $(<5 \mu \mathrm{m})$. Finally, the manufacturing process is relatively simple, safe and can be scaled up to suit commercial requirements (Doshi and Reneker, 1993; Sill and von Recum, 2008).

The migration, proliferation and morphological alignment of tendon cells within extracellular matrices are thought to be important stages of repair and are commonly used as in vitro measures of putative therapeutic scaffolds. Mouse and human fibroblast cell lines, mesenchymal 
stem cells, and primary human cells from healthy tendon samples have all been shown to change their shape and behaviour in response to electrospun fibres (Bashur et al., 2009; Bhowmick et al., 2016; Chaurey et al., 2012; Fleischer et al., 2015; Hakimi et al., 2015). What is not clear is if there is a difference in the response of tendon cells from diseased versus healthy human tendons to therapeutic electrospun fibres. Investigating this is an important step in establishing the role of electrospun fibres in treating tendinopathic tears.

The hypothesis of this study is that electrospun resorbable PDO fibres can influence the behaviour of human tendon cells from both healthy and diseased tendons despite their phenotypic differences. The aim of this study was to identify characteristic differences between diseased and healthy tendon cells and compare their responses to therapeutic electrospun fibres.

\section{Materials and methods}

\section{Collection of tendon tissue samples}

Tendon biopsies were collected from patients with informed donor consent under ethics from the Oxford Musculoskeletal Biobank (09/H0606/11) in compliance with National and Institutional ethical requirements. Hamstring tendon biopsies (healthy) were obtained from patients undergoing anterior cruciate ligament reconstruction using gracilis and semimembranosus tendons. Rotator cuff tear samples (diseased) were obtained through biopsy of supraspinatus tendons of patients over 40 years of age undergoing surgical repair for rotator cuff tears (Table 1). Supraspinatus tendon samples were typically $10 \mathrm{~mm} \times 10 \mathrm{~mm}$. Hamstring tendon samples were usually $80 \mathrm{~mm} \times 15 \mathrm{~mm}$. Biopsy samples were immediately transferred into sterile tubes containing DMEM F12 media
(Lonza, Slough, UK) in the operating theatre and were taken to the laboratory for cell isolation.

\section{Isolation of tendon cells}

Both hamstring and torn rotator cuff tissue samples were cut into approximately $2 \mathrm{~mm} \times 2 \mathrm{~mm}$ squares and transferred into 6-well plates (Corning Inc., Corning, NY, USA). Cells were initially grown from explant samples in $50 \%$ foetal calf serum (FCS) before culture in $10 \%$ FCS. Thereafter cells were grown in 'culture media' containing DMEM F12 media (Lonza, Slough, UK), $10 \%$ foetal bovine serum (Labtech, Uckfield, UK), and $1 \%$ Penicillin-Streptomycin (Thermo Fisher Scientific, Waltham, MA, USA) that was replaced every $3 \mathrm{~d}$. Once the cells had reached confluence, they were gently scraped and transferred to $10 \mathrm{~cm}$ Petri dishes (Greiner, Frickenhausen, Germany). Cells from each patient were used separately for each experiment and were used up to the 4th passage to avoid phenotypic drift experienced at higher passages (Yao et al., 2006).

\section{Electrospinning of aligned polydioxanone fibres}

Polydioxanone (PDO) fibres were electrospun using a modified version of a previously described protocol (Fig. 1) (Hakimi et al., 2015). In order to produce electrospun fibres with diameter less than $1.5 \mu \mathrm{m}$, a $7 \% \mathrm{w} / \mathrm{v}$ polymer solution of PDO (Sigma-Aldrich, Gillingham, Dorset, UK) in 1,1,1,3,3,3-Hexafluoro-2-propanol (HFP, Fluka Analytical/Sigma-Aldrich) was prepared and supplied by a syringe pump (Harvard Apparatus-PHD 2000, Kent, $\mathrm{UK}$ ) at a flow rate of $1 \mathrm{~mL} / \mathrm{h}$. An IME electrospinner (IME Technologies, Spaarpot, the Netherlands) spun the fibres at $25{ }^{\circ} \mathrm{C}$ and $30 \%$ humidity, from a single nozzle setup at voltage of 7.5-8.5 kV (Glassman, Bramley, Hampshire, UK) with a distance of $26.5 \mathrm{~cm}$ between the nozzle and the grounded electrode. PDO fibres were electrospun for between 90 to $120 \mathrm{~min}$ to achieve the requisite range of

Table 1. Characteristics of human tendon samples from hamstring and shoulder rotator cuff donors. Hamstring tendon samples came from younger patients than those of torn rotator cuff $(p<0.001)$.

\begin{tabular}{|c|c|c|c|c|c|}
\hline & & Hamstring & Suprasp & atus (rotator cuff) & \\
\hline & *H01 & Male, 31 years old & *RT01 & Male, 63 years old & $3 \mathrm{~cm}$ \\
\hline & *\# H02 & Male, 25 years old & *RT02 & Female, 46 years old & $3 \mathrm{~cm}$ \\
\hline & \# +H03 & Female, 31 years old & \# +RT03 & Female, 70 years old & $>5 \mathrm{~cm}$ \\
\hline & $\# \sim+H 04$ & Male, 22 years old & \# RT04 & Male, 68 years old & $5 \mathrm{~cm}$ \\
\hline & *H05 & Male, 34 years old & +RT05 & Female, 62 years old & $>5 \mathrm{~cm}$ \\
\hline & \# +H06 & Male, 16 years old & *\# RT06 & Female, 83 years old & $>5 \mathrm{~cm}$ \\
\hline & $\# \sim+\mathbf{H 0 7}$ & Female, 29 years old & *RT07 & Female, 64 years old & $2.5 \mathrm{~cm}$ \\
\hline & *\# H08 & Female, 26 years old & *\# +RT08 & Male, 58 years old & $>5 \mathrm{~cm}$ \\
\hline & & & +RT09 & Female, 78 years old & $>5 \mathrm{~cm}$ \\
\hline & & & \# RT10 & Male, 63 years old & $5 \mathrm{~cm}$ \\
\hline M:F & & $5: 3$ & & $4: 6$ & ns \\
\hline Age & & $26.7(\operatorname{sd} 5.8)$ & & $65.5(\mathrm{sd} 10.2)$ & $p<0.001$ \\
\hline & $*$ & Live cell imaging & $\#$ & Proliferation & \\
\hline & + & Flow cytometry & $\sim$ & Gene expression & \\
\hline
\end{tabular}




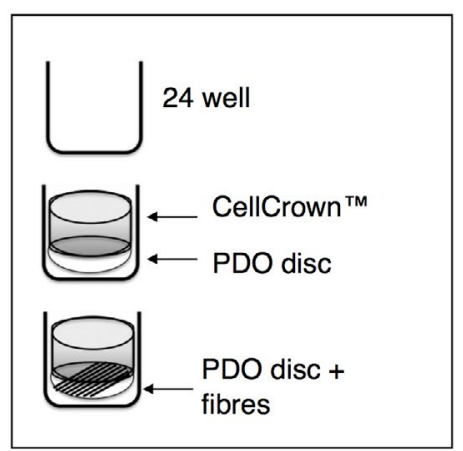

$\mathbf{a}$

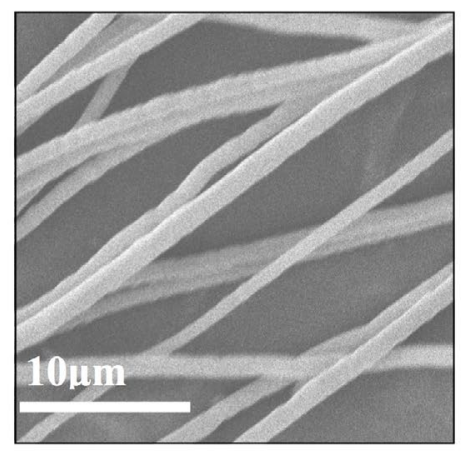

d

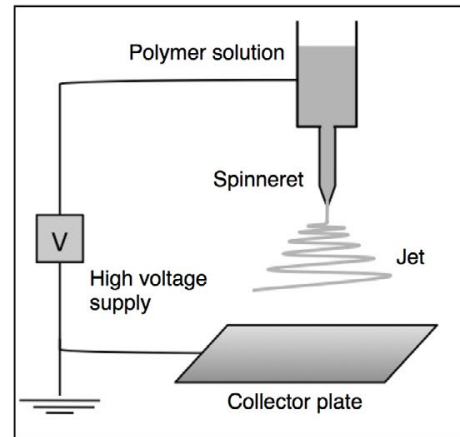

b

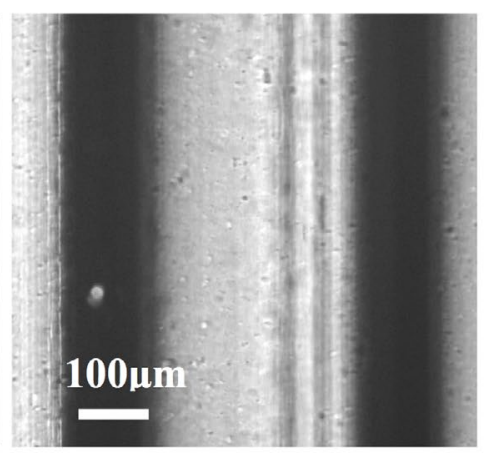

e

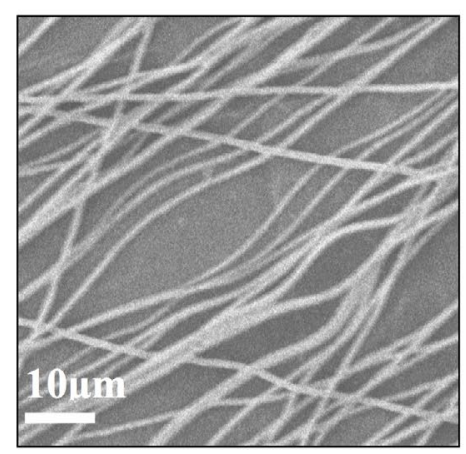

c

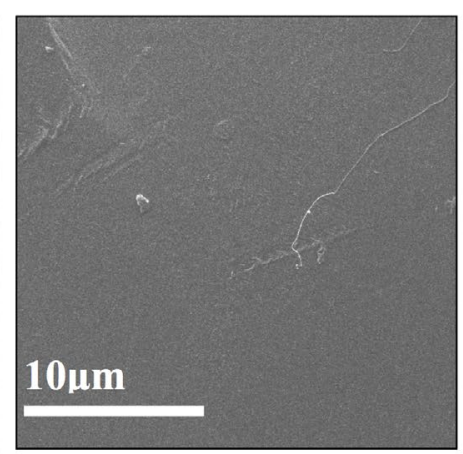

f

Fig. 1. (a) Tendon cells were cultured on culture plastic of 24-well plate, discs of PDO attached to the bottom of CellCrown ${ }^{\mathrm{TM}}$ and PDO discs + electrospun fibres. (b) PDO fibres were electrospun from a $7 \% \mathrm{w} / \mathrm{v}$ polydioxanone solution. SEM of PDO electrospun fibres (c,d). For live cell imaging assays (Fig. 2 and 3), a raft of parallel PDO monofilaments (Ethicon PDSII sutures) were used as a control PDO surface (e). SEM of PDO discs used as a control PDO surface in all other assays (f).

fibre density that was then confirmed by light microscopy. Aligned fibres were produced by electrospinning onto a collector covered with aluminium foil which was rotated at 1,000 rpm. The electrospun PDO fibres were stored under vacuum desiccation for up to three months.

\section{Preparation of scaffold constructs}

Apart from the live cell imaging assays (see 'Live cell imaging' below), discs of PDO were produced by melting $0.040 \mathrm{~g}$ of PDO between two cover-slips lined with aluminium foil at $165{ }^{\circ} \mathrm{C}$ for $120 \mathrm{~s}$. For a further $30 \mathrm{~s}$ a $10 \mathrm{~N} \mathrm{~m}$ force was applied before the discs were left to cool at room temperature and pressure. The discs were sprayed with $70 \%$ ethanol and removed with curved jewellers forceps before being sterilised in $100 \%$ ethanol for $60 \mathrm{~min}$ and rinsed 5 times with $1 \times$ PBS. They were placed in 24well culture plastic plates and firmly wedged against the well bottom by Cell Crown ${ }^{\mathrm{TM}}$ inserts (Sigma-Aldrich) to create a smooth PDO culture surface for cells. The final diameter of the discs was between 14.5 and $15.5 \mathrm{~mm}$. Discs with smaller diameters failed to cover the Cell Crown and larger discs buckled when placed in 24-well plates. Cells were then seeded directly onto the PDO disc surface. PDO electrospun fibres could be added to this construct by placing the Cell Crown ${ }^{\mathrm{TM}}$ top-down onto an appropriate sized square of aluminium sheet covered with electrospun fibres. The fibres were sprayed with $70 \%$ ethanol to help them detach. Curved jewellers forceps were used to place the fibres onto the Cell Crown ${ }^{\mathrm{TM}}$. Securing the crown helped further stretch the aligned fibres (see Fig. 1) before the construct was inverted and placed directly against the PDO disc in a 24-well plate.

\section{Live cell imaging}

Cell transfection with GFP-LifeACT

Human cells from healthy and diseased tendons were transfected with GFP-Clover-Lifeact-7 (Plasmid \#54551, (Lam et al., 2012)) using FuGENE ${ }^{\circledR}$ HD Transfection Reagent (Promega). Human tendon cells were aliquoted to a $10 \mathrm{~cm}$ Petri dish $24 \mathrm{~h}$ in advance to achieve $60-70 \%$ confluence on the day of transfection. FuGENE ${ }^{\circledR}$ HD Transfection Reagent was mixed with $0.1 \mu \mathrm{g}$ of LifeACT plasmid (A260:A280 ratio of 1.7-1.9 and concentration of $0.2-1.0 \mathrm{mg} / \mathrm{mL}$ ) at ratio of $2: 1$ and made up to the appropriate final volume with Opti-MEM I Reduced Serum Media (ThermoFisher Scientific) as per manufacturer's instructions. Cells were cultured at $37{ }^{\circ} \mathrm{C}$ in DMEM F12 (Lonza, Slough, UK) with $10 \%$ foetal bovine serum (Labtech, Uckfield, UK) but without antibiotics. The medium was changed after $48 \mathrm{~h}$ and after a total of $72 \mathrm{~h}$, 


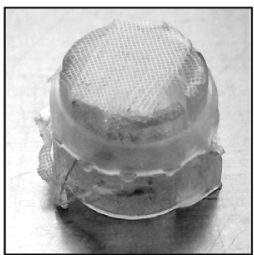

$\mathbf{a}$

b

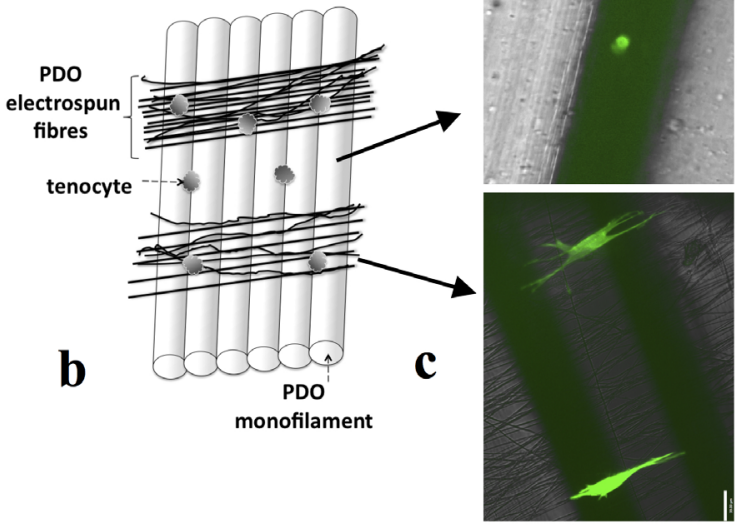

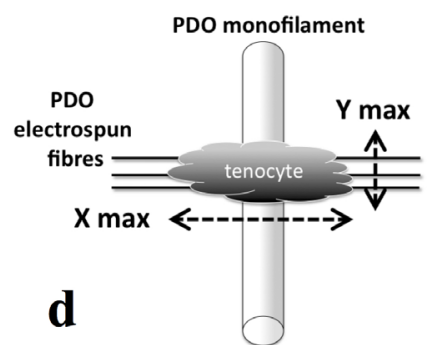

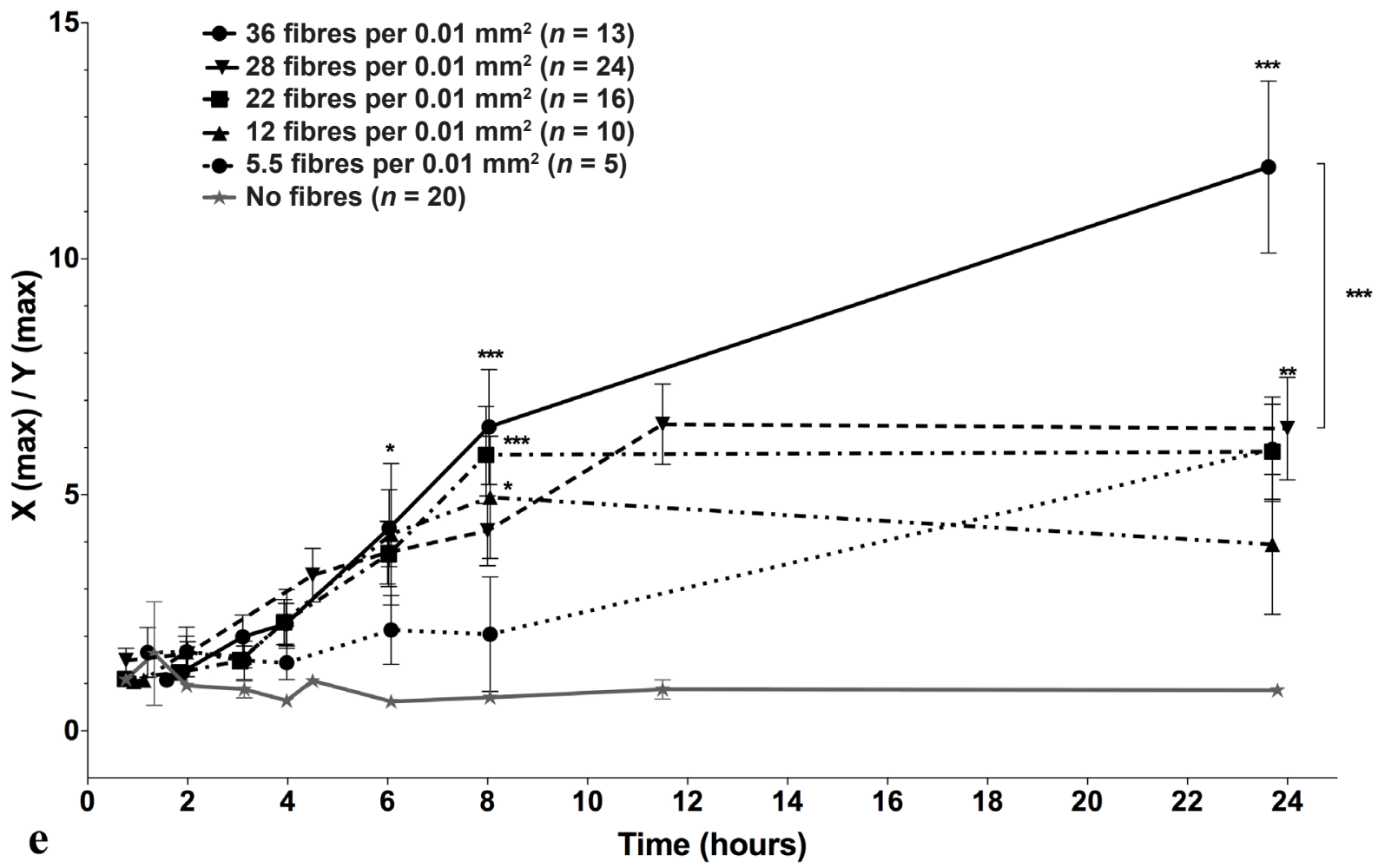

Fig. 2. (a,b) For live cell imaging assays, PDO electrospun fibres were stretched perpendicularly across a raft of parallel PDO monofilament. This was secured onto a CellCrown ${ }^{\mathrm{TM}}$ 24-well plate insert. (c) GFP-LifeAct transfected human tendon cells were seeded onto the construct and viewed with image capture wide field light microscopy. The top image shows cells on PDS monofilament alone and the bottom image shows cells on PDS monofilament + electrospun PDO fibres. (d) Changes in cell orientation in response to PDO electrospun fibres versus monofilament (control surface) were quantified by $\mathrm{X}(\max ) / \mathrm{Y}(\max )$. (e) The change in $\mathrm{X}(\max ) / \mathrm{Y}(\max )$ of GFP labelled primary human hamstring cells in response to PDO monofilament/electrospun fibre constructs over a $24 \mathrm{~h}$ period. The rate of cell elongation was dependent on the density of electrospun PDO fibres. Cells seeded onto PDO electrospun fibres with densities greater than 22 fibres $/ 0.01 \mathrm{~mm}^{2}$ exhibited significantly greater change in $\mathrm{X}(\max ) / \mathrm{Y}(\max )$ compared to lower fibre densities $(\mathrm{X}(\max ) / \mathrm{Y}(\max )>5.96$ at $24 \mathrm{~h}, p<0.01)$. Tendon cells seeded onto control surface of PDO monofilaments (Ethicon PDSII sutures) without PDO electrospun fibres (stars) did not show the same conformational change $(\mathrm{X}(\max ) / \mathrm{Y}(\max )<0.86$ at $24 \mathrm{~h}, p<0.001$ compared to all other groups). Data are pooled from technical repeats and ' $n$ ' represents the number of observed cells over a $24 \mathrm{~h}$ period. 
fresh medium, with $2.5 \mathrm{mg} / \mathrm{mL} \mathrm{G}-418 /$ neomycin (based on previous titration assays), was added to remove cells that were not transfected with the LifeACT plasmid.

\section{Preparation of PDO electrospun fibre constructs}

'PDSII' monofilament PDO sutures (PDS) of $0.3 \mathrm{~mm}$ diameter (Ethicon, Johnson and Johnson Medical, Livingston, West Lothian, UK) were used as a smooth control surface in all live cell imaging assays because they allowed sufficient visible and UV light to pass for wide field microscopy. A raft of parallel aligned 2 ' 0 ' PDS monofilament sutures was placed over the top of a 24-well plate Cell Crown ${ }^{\mathrm{TM}}$ insert (Sigma-Aldrich, Fig. 2). Aligned electrospun PDO fibres were then stretched over this surface at $90^{\circ}$ to the PDS monofilaments. The monofilament / electrospun fibre construct was secured in place by the crown of the CellCrown ${ }^{\mathrm{TM}}$ insert. By partially covering the raft of PDS with electrospun fibres, it was possible to have areas with and without fibres on the same construct. The construct was sterilised in $100 \%$ ethanol for $60 \mathrm{~min}$ and rinsed five times in sterile $1 \times$ PBS.

\section{Cell seeding onto construct and live imaging}

In order for sufficient cells to adhere to the electrospun fibres for the live cell imaging assays, $500 \mu \mathrm{L}$ of a suspension of cells at $1 \times 10^{\wedge}$ cells $/ \mathrm{mL}$ in culture medium (DMEM F12 media, $10 \%$ foetal bovine serum and $1 \%$ PenicillinStreptomycin) was seeded onto the PDO monofilament/ fibre CellCrown ${ }^{\mathrm{TM}}$ construct. Cells were allowed to adhere for 10 min before the CellCrown ${ }^{\mathrm{TM}}$ construct was inverted and firmly placed into a well of a glass bottomed 24-well plate containing $750 \mu \mathrm{L}$ of culture medium.

The construct was kept approximately $2 \mathrm{~mm}$ above the floor of the 24-well plate to ensure that the cells were close to the microscope objective, without being in contact with the glass bottom. During the $24 \mathrm{~h}$ live imaging assay, cells were kept in a sealed chamber with $\mathrm{CO}_{2}$ inflow and at a temperature of $37^{\circ} \mathrm{C}$. A Nikon Eclipse TE2000-E wide field live-cell imaging microscope was used to capture images and Volocity v6.3 was used to measure the $\mathrm{X}(\max ): \mathrm{Y}(\max )$ ratio (see Fig. 2). In order to isolate the effect of topography on cell morphology, any cell that was part of a cluster was excluded from the analysis. Statistical significance was determined by 2 way ANOVA performed by GraphPad Prism v5 software (GraphPad Software Inc., California, USA).

\section{Cell proliferation}

Approximately 15,000 human tendon cells were seeded onto (i) the (plastic) base of a 24-well tissue culture plate, (ii) PDO discs or (iii) PDO discs + aligned PDO electrospun fibres (see 'Preparation of electrospun polydioxanone fibres and control surfaces', above) and incubated at $37{ }^{\circ} \mathrm{C}$ with $6 \% \mathrm{CO}_{2}$. Cell proliferation was quantified using alamarBlue ${ }^{\circledR}$ Assay, which has previously been validated (Ahmed et al., 1994; Voytik-Harbin et al., 1998). After $24 \mathrm{~h}$ the PDO constructs were transferred into fresh 24-well plates to exclude from the analysis any cells not attached to the PDO. $1 \mathrm{~mL}$ of TrypLE ${ }^{\mathrm{TM}}$ (ThermoFisher Scientific) was added to the original 24-well plates, and PDO discs in the case of PDO discs + electrospun fibres, and cell counting for each assay confirmed that virtually all the cells adhered to the electrospun fibres under these conditions. This same process was also used for the immunofluorescence and gene expression analysis (see below). The constructs were incubated for $4 \mathrm{~h}$ in $5 \%$ alamarBlue ${ }^{\circledR}$ (Invitrogen) in standard media at day 1 , day 4 and day 7 . Fluorescence was measured at $485 \mathrm{~nm}$ excitation and $520 \mathrm{~nm}$ emission using a FLUOstar optima microplate reader (BMG Labtech, Ortenberg, Germany) and compared to a cell density calibration curve of hamstring cells cultured on a 24-well plate under the same conditions. Technical triplicates were performed for each biological sample.

\section{Immunofluorescence analysis and monoclonal antibodies}

Hamstring and diseased rotator cuff tendon cells were detached using $1 \mathrm{~mL}$ of TrypLETM (ThermoFisher Scientific) pre-warmed to $37^{\circ} \mathrm{C}$. Cells were then washed three times in $1 \times$ PBS containing $0.1 \% \mathrm{NaN}_{3}$ and $0.1 \%$ BSA and were labelled directly with fluorescently conjugated monoclonal antibodies (mAb) or isotype control mAb. For flow cytometry (FACS) staining, antiCD9 (H19a) PE-conjugated mouse IgG1k, anti-CD10 (H10a) BV421-conjugated mouse IgG1k, anti-CD26 (BA5b) FITC-conjugated mouse IgG2a, anti-CD106 PEconjugated mouse IgG1k and anti-CD34 (581) PerCPconjugated mouse IgG1k (BioLegend, CA, USA) were used to label cells in PBS containing $0.1 \% \mathrm{NaN}_{3}, 1 \%$ $\mathrm{BSA}$ and FcR human blocking reagent (Miltenyl Biotech) at $4{ }^{\circ} \mathrm{C}$. When required, the cells were then washed in PBS containing $0.1 \% \mathrm{NaN}_{3}$ and $0.1 \%$ BSA. Cells were fixed in PBS containing $0.1 \% \mathrm{NaN}_{3}, 1 \% \mathrm{BSA}$ and $2 \%$ formaldehyde. Post compensation twelve-colour analysis was performed with a LSR-Fortessa flow cytometry analyser (BD Biosciences) using 4 lasers; violet (405 nm), blue $(488 \mathrm{~nm})$, yellow-green $(561 \mathrm{~nm})$ and red $(640 \mathrm{~nm})$. The analysis gate was set on the forward $(155 \mathrm{~V})$ and side scatters $(225 \mathrm{~V})$ to eliminate cell debris, and dead cells were further excluded using Fixable Viability Dye eFluor ${ }^{\circledR}$ 780 (BioLegend). Positive and negative gate analysis was determined with reference to corresponding samples incubated with isotype control mAb. The percentage of live cells that expressed significant levels of cell surface proteins was determined with reference to corresponding cells incubated with isotype control antibodies.

\section{Gene expression; RNA extraction, cDNA synthesis and RT-qPCR}

Each type of construct was seeded with approximately 15,000 tendon cells. Following $7 \mathrm{~d}$ in culture medium, tendon cells were detached using $1 \mathrm{~mL}$ of TrypLETM (ThermoFisher Scientific), pre-warmed to $37^{\circ} \mathrm{C}$. After washing with $1 \times$ PBS (Sigma-Aldrich), the cell pellet was resuspended in $350 \mu \mathrm{L}$ of RNeasy Mini Kit RLT buffer (Qiagen) and immediately placed in $-80{ }^{\circ} \mathrm{C}$ for storage. mRNA extraction and purification was achieved using RNeasy Mini Kit (Qiagen), following the manufacturer's instructions. mRNA purity and concentration was measured using a Nanodrop ND1000 Spectrophotometer (Nanodrop Technologies, Willington, DE, USA). mRNA samples with a 260:280 ratio greater than 1.6 and a concentration 
$\mathbf{a}$

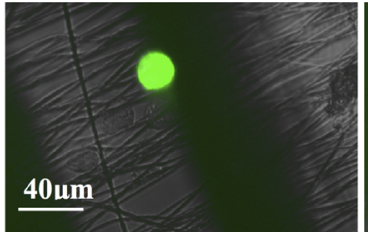

Time 0

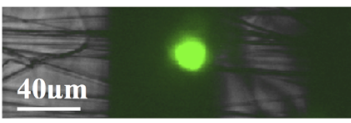

b

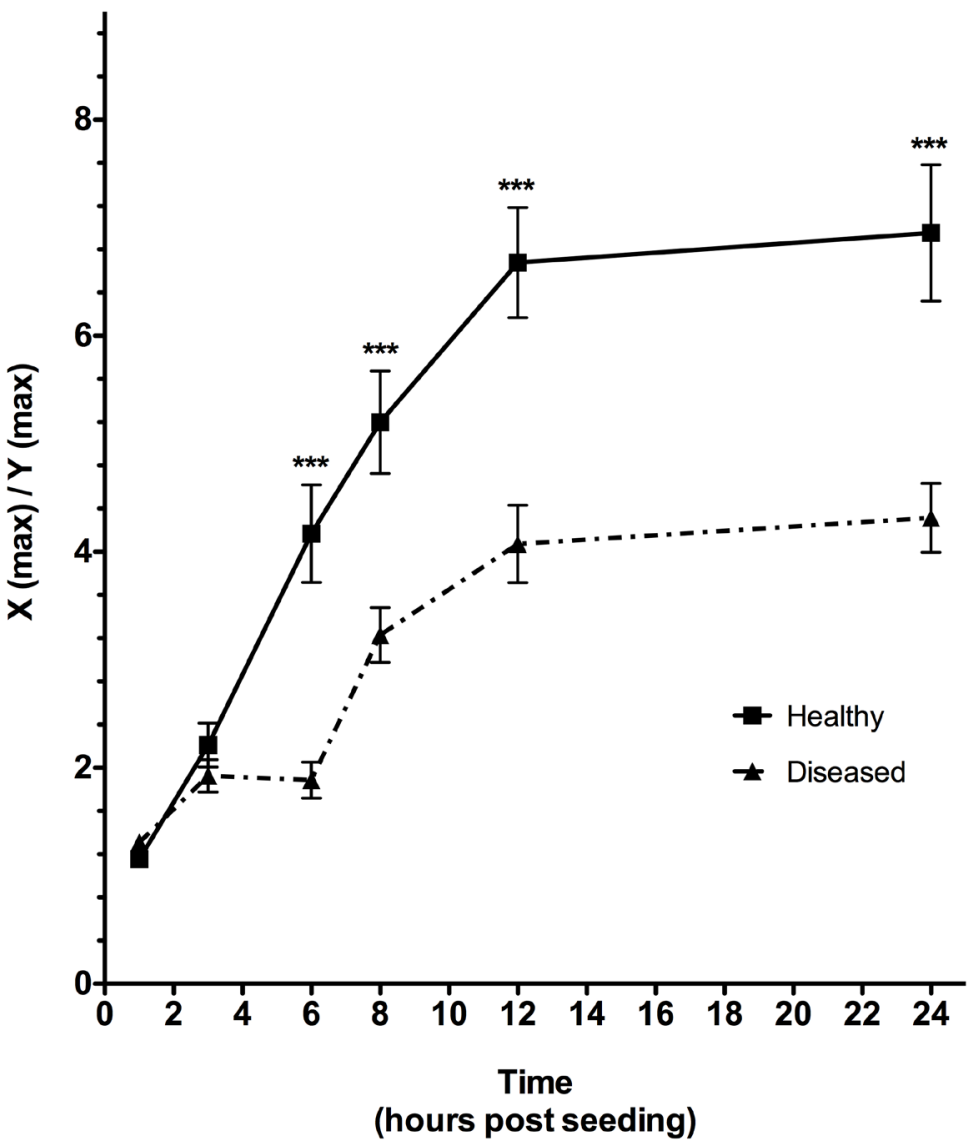

Fig. 3. Primary human cells from healthy hamstring tendons (healthy; square) and from torn rotator cuff tendons (diseased; triangle) were transfected with GFP-LifeAct and seeded onto PDO monofilament/ electrospun fibre constructs (see Fig. 2). Live cell capture imaging was performed using a wide field microscope over a $24 \mathrm{~h}$ period. Based on previous results, electrospun fibre density of 35 fibres per $0.01 \mathrm{~mm}^{2}$ was used for both groups. An example of healthy (a) and diseased (b) tendon cells are illustrated at time 0 versus $12 \mathrm{~h}$. (c) Diseased tendon cells (triangle) and healthy tendon cells (squares) elongated along PDO electrospun fibres over a $24 \mathrm{~h}$ period. After $6 \mathrm{~h}$ the $\mathrm{X}(\max ) / \mathrm{Y}(\max )$ of healthy tendon cells (square, 4.17) was significantly greater than that of diseased tendon cells from torn rotator cuff tendons (1.89, $p<0.001, n>140$ cells combined from four biological replicates per group). greater than $5 \mathrm{ng} / \mu \mathrm{L}$ were used in subsequent assays. cDNA was generated using a High-Capacity cDNA Reverse Transcription Kit (ThermoFisher/Applied Biosystems) in the presence of RNasin ${ }^{\circledR}$ Plus RNase Inhibitor (Promega) for $10 \mathrm{~min}$ at $25^{\circ} \mathrm{C}, 60 \mathrm{~min}$ at $37^{\circ} \mathrm{C}$ and $5 \mathrm{~min}$ at $85^{\circ} \mathrm{C}$. cDNA samples were stored in RNAse free water at $-20{ }^{\circ} \mathrm{C}$. RT-qPCR was performed with a ViiA7 real-time PCR machine (Applied Biosystems) using Fast SYBR ${ }^{\circledR}$ Green Master Mix (ThermoFisher/Applied Biosystems) and the following QuantiTect primers for type-I collagen (COL1A1), type-III collagen (COL3A1), type-VI collagen (COL6A1), scleraxis (SCXB) and tenomodulin (TNMD) (Qiagen, Hilden, Germany). Glyceraldehyde 3-phosphate dehydrogenase $(G A P D H)$ and TATA-binding protein $(T B P)$ were used as endogenous reference genes. Gene expression was calculated using the comparative CT method (Schmittgen and Livak, 2008).

\section{Statistical analysis}

GraphPad Prism v5 software (GraphPad Software Inc., California, USA) was used to confirm normality of cell shape using Shapiro-Wilk testing and performed 2 way ANOVA on changes in cell morphology during live cell imaging, cell proliferation and flow cytometry assays. Kruskal-Wallis test, with Dunn's correction for multiple testing, was performed using Prism v5 for RT-qPCR gene expression assays.

\section{Results}

Human cells were obtained from hamstring tendons and torn rotator cuff tendons (RCT), allowing an in vitro comparison of healthy and diseased tendon cells respectively. Cell behaviour on electrospun PDO was 
Day 4 versus day 1

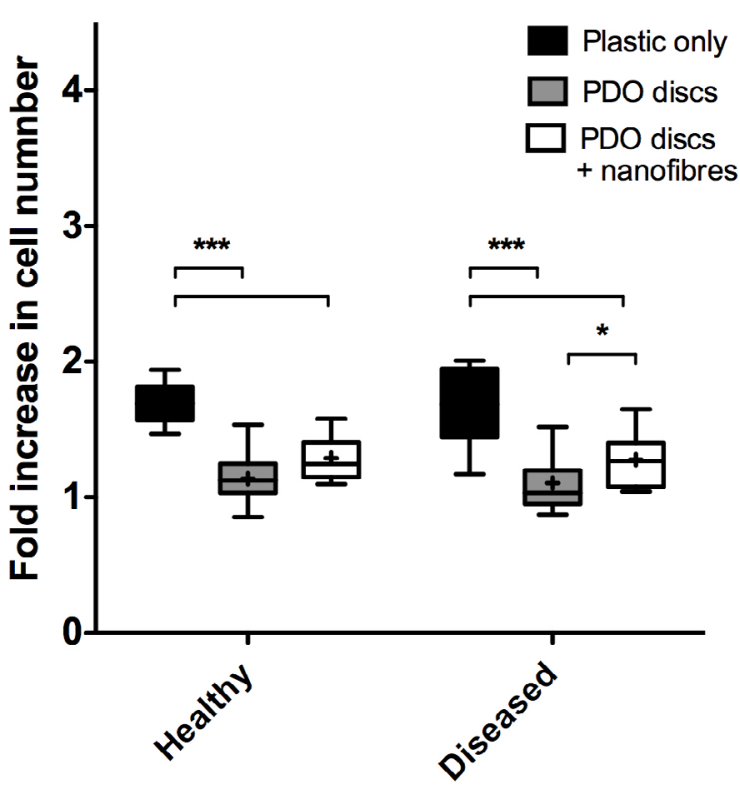

$\mathbf{a}$

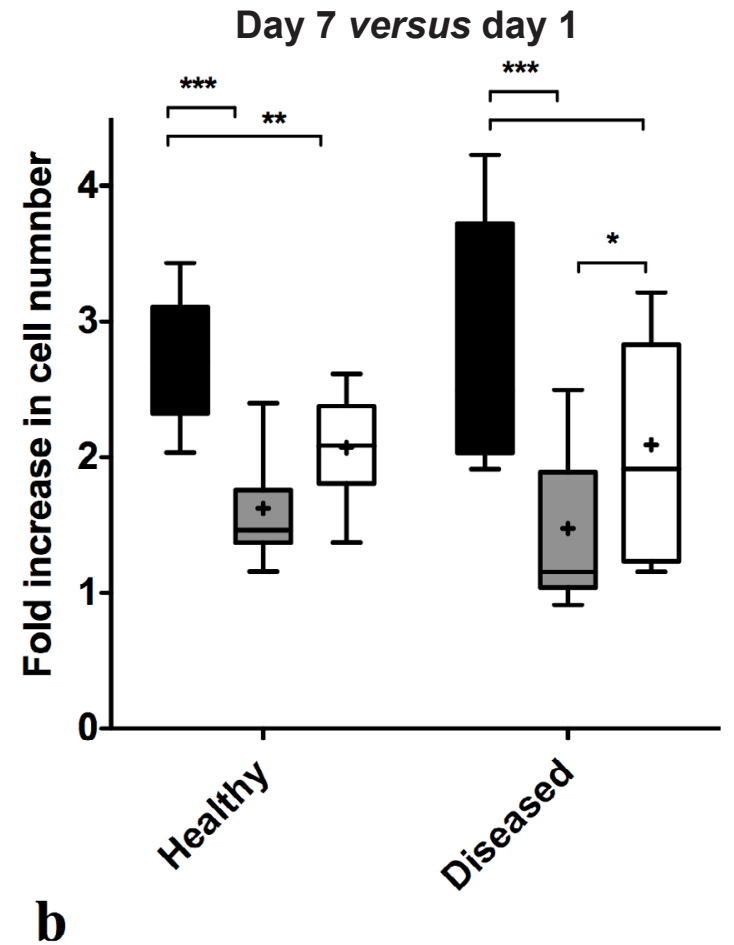

Fig. 4. Approximately 15,000 primary human cells from healthy hamstring tendon and diseased torn rotator cuff tendon samples were seeded onto (i) culture plastic of 24-well plate, (ii) PDO discs or (iii) PDO discs + electrospun fibres at day 0. Cell numbers were quantified using alamarBlue ${ }^{\circledR}$ assay at day 1,4 and 7 . Proliferation rate was calculated as the fold increase in cell number from day 1 to day 4 (a) and from day 1 to day 7 (b). Healthy and diseased tendon cells cultured on tissue culture plastic (black) had significantly higher proliferation rates at day 4 and day 7 than those cultured on PDO discs (grey) or PDO discs + electrospun fibres (white, $p<0.001$ ). The proliferation rate of diseased tendon cells cultured for $7 \mathrm{~d}$ on PDO discs + electrospun fibres was significantly greater than on PDO discs alone. (2.10 vs. 1.74 respectively, $p<0.05$. Healthy, $n=6$ and diseased, $n=5$, technical triplicates).

compared to tissue culture plastic and discs of PDO in all assays (Fig. 1) except for live cell imaging in which PDO monofilament suture was used as a control surface (Fig. 2a-d).

Wide-field live cell image capture microscopy was used to investigate the immediate morphological response of primary human tendon cells to electrospun fibres. GFP labelled healthy and diseased tendon cells were seeded onto aligned PDO electrospun fibres of $1.30 \mu \mathrm{m}$ diameter (Fig.1 c-d, s.d. 0.38) or PDO monofilament suture of approximately $300 \mu \mathrm{m}$ diameter (Fig. 1e). A scaffold was designed in which aligned PDO electrospun fibres of varying density were stretched at $90^{\circ}$ over PDO monofilament suture (Fig. 2a). This orthogonal orientation of PDO electrospun fibres to PDO monofilaments meant that preferential migration and alignment of tendon cells along the electrospun fibres could be measured by an increase in the ratio of the maximal $\mathrm{X}$ dimension compared to the maximal Y dimension (Fig. 2b-d). Areas of the scaffold were kept bare of PDO electrospun fibres and had only PDO monofilament, representing a negative control surface.

Within $4 \mathrm{~h}$ of coming into contact with the scaffold, healthy tendon cells rapidly changed their shape, aligning and elongating along individual PDO electrospun fibres (Fig. 2c,e). This cellular morphological response was dependent on fibre density. Fig. 2e demonstrates that as the density of aligned PDO electrospun fibres was increased from 5 fibres per $0.01 \mathrm{~mm}^{2}$ up to 36 fibres per $0.01 \mathrm{~mm}^{2}$, the change of $\mathrm{X}(\max ) / \mathrm{Y}(\max )$ with time significantly increased to a final ratio of 11.9 (s.d. 6.5) for 36 fibres per $0.01 \mathrm{~mm}^{2}$ ( $p<0.0001 v s$. all other groups). In comparison, hamstring cells seeded onto PDO monofilament without electrospun fibres (Fig. 2e; stars) demonstrated very little morphological change over the $24 \mathrm{~h}$ period and maintained similar $\mathrm{X}$ versus $\mathrm{Y}$ dimensions $(\mathrm{X}(\max ) / \mathrm{Y}(\max ) \sim 1)$.

Having demonstrated that healthy tendon cells elongate along electrospun PDO fibres, we investigated whether diseased cells from chronic tendinopathic rotator cuff tears (RCT) were also capable of a similar response. Based on the results in Fig. 2, an electrospun fibre density of approximately 35 per $0.01 \mathrm{~mm}^{2}$ was chosen (fibre densities greater than 45 per $0.01 \mathrm{~mm}^{2}$ limited visibility). As before, human cells from healthy hamstring tendon donors spread along the aligned PDO electrospun fibres such that their maximal X dimension was a mean of 6.95 (s.d. 5.7) times that of the maximal Y dimension (Fig. 3c). Cells from diseased tendon also aligned and elongated along PDO electrospun fibres, but at a slower rate (first derivative of $0.30 \mathrm{vs} .0 .55$ of healthy cells at $4 \mathrm{~h}$ ) and with a final $\mathrm{X}(\max ) / \mathrm{Y}(\max )$ of 4.31 (s.d. 3.1$)$ after $24 \mathrm{~h}(p<0.001)$. 
CD106neg

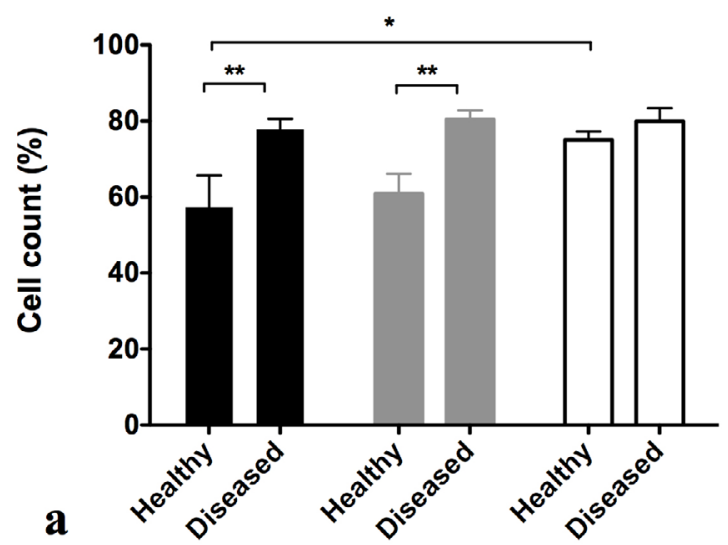

$\underline{\text { CD26+ cells }}$

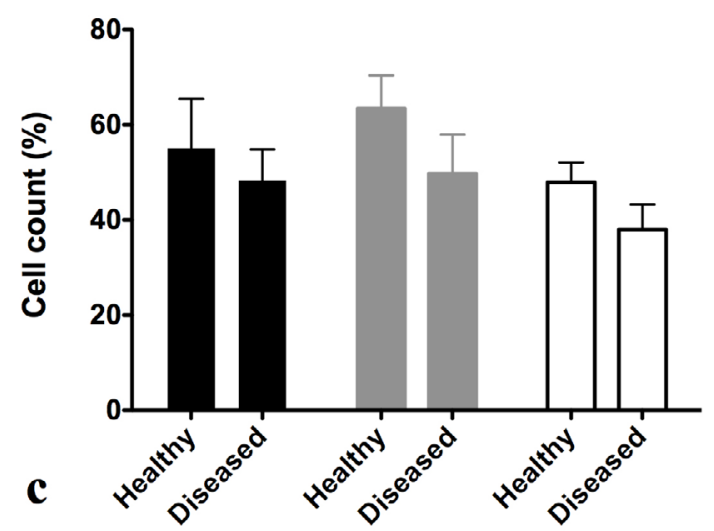

$\underline{\text { CD10+Cells }}$

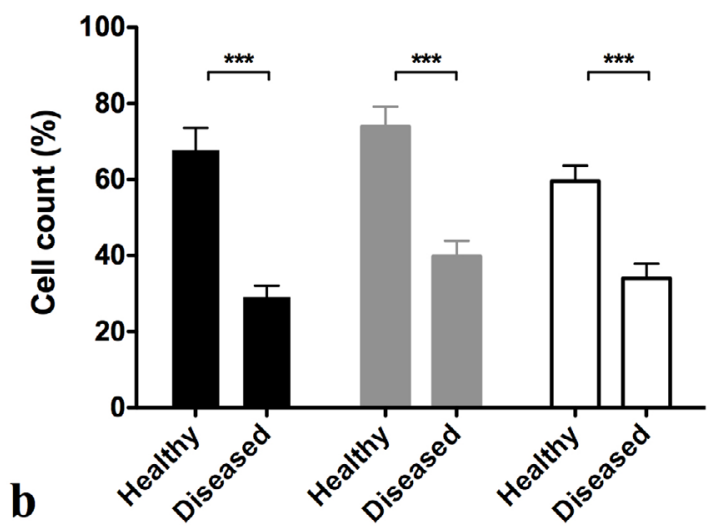

Total CD106neg CD10+CD26+

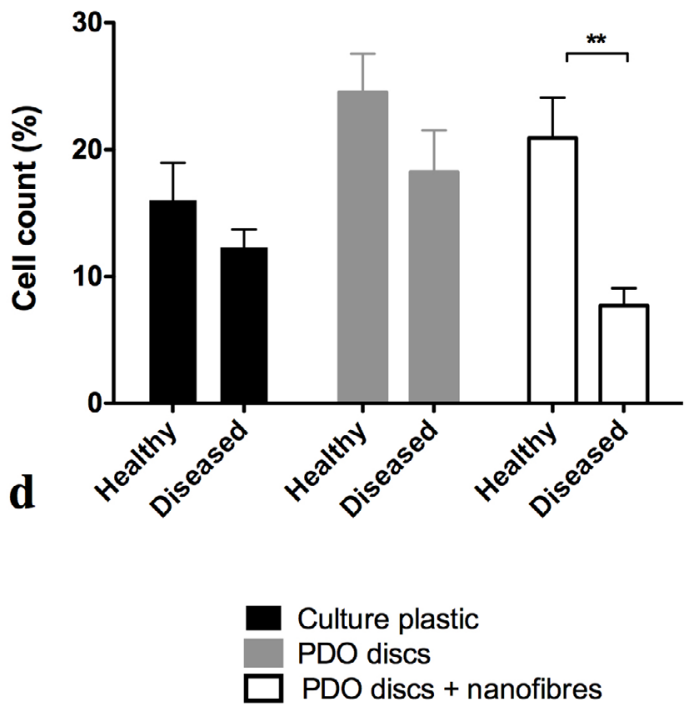

Fig. 5. Primary human cells from healthy and diseased tendon samples were seeded onto culture plastic of 24 -well plate (black), PDO discs (grey) or PDO discs + PDO electrospun fibres (white) at day 0. At day 3, tendon cells were directly labelled with fluorescently conjugated monoclonal antibodies (mAb) against CD106, CD10 and CD26. A significantly greater percentage of diseased tendon cells on culture plastic and PDO discs were CD106 negative compared with healthy tendon cells (a). The percentage of CD106 negative healthy tendon cells increased when cultured on PDO + electrospun fibres compared to culture plastic alone. (b) Significantly greater expression of CD10 expression was found on at least $70 \%$ of healthy tendon cells versus $30 \%$ of diseased tendon cells cultured on all three surfaces $(p<0.001)$. There was no significant difference in CD26 expression $(\mathbf{c}) .21 \%$ of healthy tendon cells compared to $8 \%$ of diseased tendon cells were $\mathrm{CD} 106^{\text {neg }} \mathrm{CD} 10^{+} \mathrm{CD} 26^{+}$when cultured on electrospun fibres $(p<0.01$, d). $(n=4$, technical duplicates $)$.

The fold increase in cell number from day 1 to day 4 (Fig. 4a) and from day 1 to day 7 (Fig. 4b) was measured using an alamarBlue ${ }^{\circledR}$ assay for healthy and diseased tendon cells. There was no significant difference between the proliferation rate of healthy and diseased tendon cells on culture plastic of 24-well plates. In both cases, the proliferation rate on culture plastic was significantly greater than on PDO discs or PDO discs + electrospun fibres $(p<0.001)$. There was a significant increase in the proliferation rate of diseased tendon cells cultured on PDO discs + electrospun fibres compared with PDO discs alone at day 4 (mean fold increase of $1.3 v s .1 .1, p<0.05$ ) and at day 7 (mean fold increase of 2.1 vs. 1.5, $p<0.05$ ). A similar trend was seen for healthy tendon cells but was not statistically significant.

In order to help characterise phenotypic differences between cells from healthy and diseased tendons in response to PDO electrospun fibres, flow cytometry was 
COL1A1

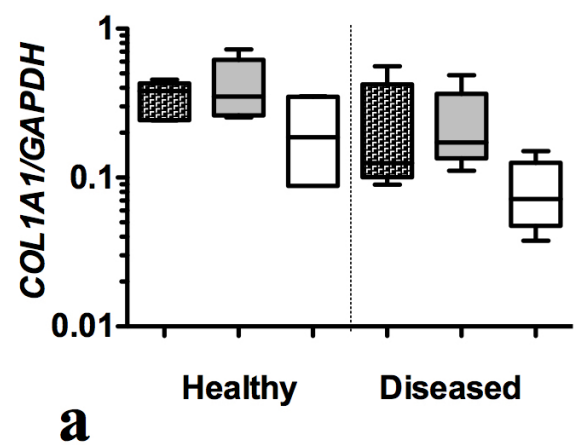

COL1A1 relative to COL3A1

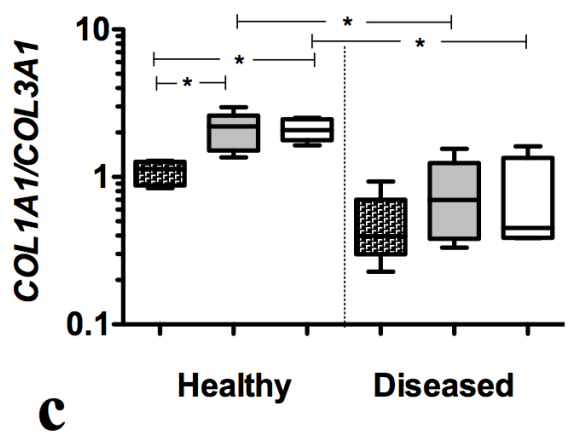

SCXS

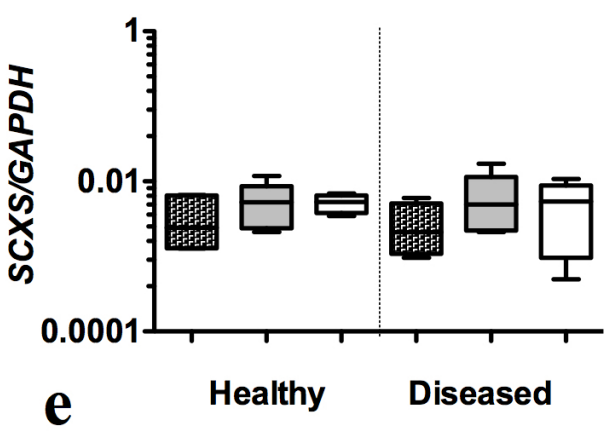

COL3A1

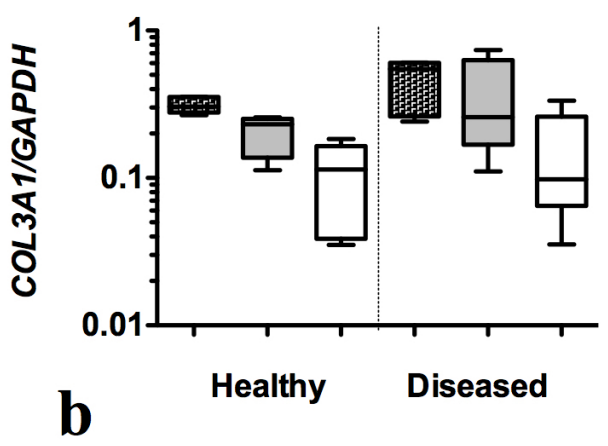

COL6A1

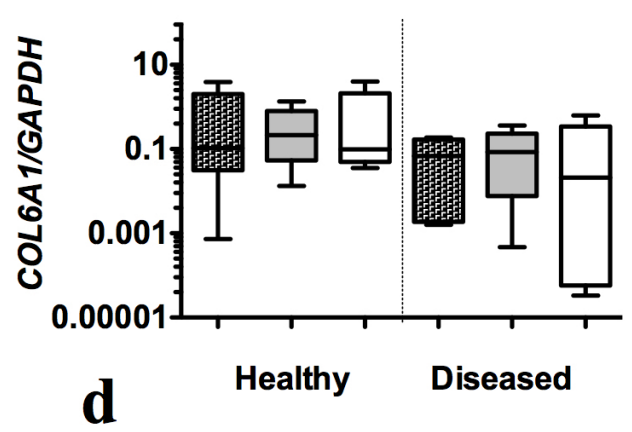

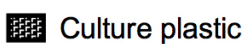

$\square$ PDO discs

$\square$ PDO discs

+ nanofibres

Fig. 6. After $7 \mathrm{~d}$ of culture on culture plastic (black hashed), PDO discs (grey) and PDO discs + electrospun fibres (white) mRNA expression of COL1A1 (a), COL3A1 (b), COL6A1 (d) and SCXS (e) was analysed with RT-qPCR. The relative expression of COL1A1:COL3A1 was significantly greater in healthy tendon cells when cultured on PDO or PDO + electrospun fibres compared with culture plastic. COL1A1:COL3A1 expression in healthy tendon cells was significantly greater than diseased tendon cells on PDO and PDO + electrospun fibres (c). (Hamstring, $n=6$ and $\mathrm{RCT}, n=5$, technical triplicates).

performed using fluorescent monoclonal antibodies against CD106, expressed on undifferentiated mesenchymal stem cells, as well as CD10 and CD26, expressed on adult human dermal fibroblasts. A higher percentage of diseased tendon cells on culture plastic and PDO discs were CD106negative compared with healthy tendon cells (Fig. 5a; mean $78 \%$ vs. $57 \%$ respectively, $p<0.01$ ). This was not the case when cells were cultured on PDO discs + electrospun fibres which resulted in a significant increase in the number of CD106-negative healthy tendon cells from $57 \%$ to $75 \%$ $(p<0.05)$. The proportion of CD106-negative diseased tendon cells did not vary significantly with the different culture conditions.

No significant difference in CD26 expression was found between healthy and disease tendon cells and there was no significant change in relation to the different culture surfaces (Fig. 5c). Significantly more healthy tendon cells expressed CD10 on their cell surface compared to diseased tendon cells when exposed to culture plastic (mean $68 \%$ vs. $29 \%)$, PDO discs (74 \% vs. $40 \%)$ or PDO discs + electrospun fibres (60\% vs. $34 \%, p<0.001$. Fig. 5b). No significant change in expression of CD10 alone was 
observed for healthy or diseased tendon cells in relation to culture on different surfaces. There was a difference in the percentage of healthy versus diseased cells cultured on PDO discs+electrospun fibres that co-expressed $\mathrm{CD} 106^{\text {neg }} \mathrm{CD} 10^{+} \mathrm{CD} 26^{+}(21 \%$ vs. $8 \%$ respectively, $p<0.01$, Fig. 5d).

Reverse transcriptase quantitative PCR demonstrated a significant increase in the ratio of COL1A1:COL3A1 mRNA expression in healthy compared with diseased tendon cells after $7 \mathrm{~d}$ of culture on both PDO discs and PDO discs + electrospun fibres (Fig. 6c, $p<0.05$ ). There was a significant increase in the ratio of COL1A1:COL3A1 mRNA expression by healthy tendon cells when cultured on PDO discs and PDO discs + electrospun fibres compared with the ratio on culture plastic $(p<0.05)$. A similar trend was seen for diseased tendon cells but this was not significant. No significant difference in expression of COL6A1 or SCXS was found after a total of $7 \mathrm{~d}$ of culture (Fig. 6a-e).

\section{Discussion}

This is the first study to compare directly the responses of human cells from healthy and diseased tendons to electrospun fibres. Electrospun PDO fibres were able to modify the behaviour of tissue resident human cells from both healthy and also diseased tendons. Cells from healthy tendons differed in vitro from those of diseased tendons in terms of dynamic cell morphology, COL1A1:COL3A1 mRNA expression and cell surface proteins.

In order to follow the morphological response of human tendon cells to physical stimulation by PDO electrospun fibres, we designed a competitive live cell imaging assay. Aligned PDO electrospun fibres were placed orthogonally across a control surface of much larger PDO monofilaments; over $200 \times$ the diameter. This ensured that GFP-labelled tendon cells only came into contact with PDO during the assay. It also meant that any conformation change of cells along either the PDO monofilament or electrospun fibres could be clearly demonstrated and quantified without involving bespoke in vitro models (Kim et al., 2009) with limited direct therapeutic application. Tendon cells from healthy hamstring tendons and diseased RCT samples markedly changed their shape to mimic the electrospun fibre contours and elongated along the aligned fibres. In keeping with previous studies, this response was dependent on fibre density (Bashur et al., 2009; Fleischer et al., 2015; Lee et al., 2005). In general, the greatest change in morphology was observed within the first $12 \mathrm{~h}$, thereafter the rate of change decreased. The hamstring cells seeded onto the higher fibre density ( 36 per $0.01 \mathrm{~mm}^{2}$ ) in Fig. 2e demonstrated exceptional change beyond $12 \mathrm{~h}$ and resulted in a final $\mathrm{X}(\max ) / \mathrm{Y}(\max )$ of 11.9 (compared to 6.95 in Fig. 3c). This group comprised fewer hamstring cells from fewer tendon donors and it is possible that the observed difference relates to biological variation that would normalise with greater numbers. The response of diseased cells to different PDO electrospun fibre densities was not pursued in this study. Diseased cells may respond optimally to a different range of fibre density than healthy cells.

Chaurey et al. have shown that cell directionality is also dependent on fibre diameter (Chaurey et al., 2012). In our study, fibre diameter was kept constant at $1.30 \mu \mathrm{m}$ and a fibre density of 35 fibres per $0.01 \mathrm{~mm}^{2}$ (based on results in Fig. 2) was used in subsequent assays to explore the differential responses of healthy and diseased tendon cells. This morphology assay may prove a useful outcome measure to explore the effects of fibre diameter, density, porosity, composition and alignment on cell behaviour (Gomes et al., 2015). Such work would directly inform the design of therapeutic electrospun scaffolds to help repair tendon tears. One important limitation is that the live cell imaging assay preferentially selects cells that are immediately adherent to the electrospun fibres. It may be interesting to investigate other differential characteristics of this selected group.

Cells from diseased rotator cuff samples initially responded to electrospun fibres at a slower rate than healthy cells, but nonetheless underwent a similar change in morphology. This is the first comparative demonstration that cells from chronically diseased tendons retain the ability to respond to external biomechanical cues. In addition, culture of diseased RCT cells on PDO electrospun fibres resulted in a significant increase in cell proliferation compared with PDO discs alone. Although a similar trend was seen for healthy hamstring tendon cells, it failed to reach significance. One possible explanation is that healthy cells achieved high proliferation rates irrespective of the trial surface.

Cell augmentation procedures, including extracorporeal cell culture with implantation, mesenchymal stem cells and induced pluripotent stem cells, have arisen partly because of a lack of confidence in the regenerative properties of resident cells in tendinopathic tissue. Many of the cell implantation strategies continue to face concerns over resource consumption, patient safety, quality control and manufacturing standardisation. In this context, the ability of cells from diseased tendons to grow on electrospun fibres supports the development of these absorbable scaffolds as a commercially viable augment to diseased tendon repair. However, these two important parameters, integration and cell growth, need to be demonstrated in vivo or in clinical trails to strengthen the case for these bioactive scaffolds.

The ratio of COL1A1:COL3A1 mRNA expression of both healthy and diseased cells tended to increase when cells were cultured on PDO electrospun fibres compared with PDO discs or culture plastic, and a significant increase in the ratio was found for healthy cells. Similarly, when cells were cultured on either PDO discs or PDO discs + electrospun fibres, the ratio of COL1A1:COL3A1 mRNA expression was significantly greater in healthy cells compared to diseased cells. A decrease in the ratio of type I: type III collagen has been reported in tendinopathic samples (de Mos et al., 2007; Ireland et al., 2001), whereas an increase in this ratio was demonstrated in primary human fibroblasts grown on synthetic, rather than biological, scaffolds (Smith et al., 2016). Taken 
together, these results suggest that electrospun scaffolds are bioactive and able to regulate at least healthy tendon cell mRNA expression under these conditions. Further work may demonstrate whether changes in electrospun scaffold design can influence diseased tendon cells to express healthy tendon matrix proteins such as type I and type III collagen.

We found no significant difference between the groups in the expression of type VI collagen, scleraxis or tenomodulin (data not shown) after $7 \mathrm{~d}$ of in vitro culture (Shukunami et al., 2006). This study was limited to early in vitro outcomes and more comprehensive study is required to investigate the effect of biophysical stimulation on extracellular matrix production.

The heterogeneity of tendon derived cells and the absence of well described phenotypic groups continues to be a major limitation in studying their responses in vitro and in vivo. Flow cytometry offers one way in which fibroblasts can be sub-classified. However, previous studies have so far revealed only a handful of cell surface proteins that are preferentially expressed on fibroblasts as opposed to other derivatives of mesenchymal stem cells (Cappellesso-Fleury et al., 2010; Halfon et al., 2011; Mohanty et al., 2014). These include CD106, CD26, CD10 and CD9. Human adult dermal and lung fibroblasts reportedly showed decreased expression of CD106 compared with mesenchymal stem cell lines, suggesting that this protein is lost from the surface of differentiated cells (Halfon et al., 2011). CD106 (VCAM-1) is a membrane protein of the immunoglobulin super family and can be unregulated in response to proinflammatory TNF-alpha and IL-1 (Simmons et al., 1992). Expression of CD106 gene was also shown to decrease after osteogenic differentiation of mesenchymal stem cells (Liu et al., 2008). We found that a greater proportion of diseased tendon cells were CD106 $6^{\text {neg }}$ compared to hamstring cells. This difference was annulled as a higher percentage of healthy tendon cells were CD106 ${ }^{\text {neg }}$ when cultured on PDO electrospun fibres (Fig. 5). The expression of two cell surface proteins found on differentiated dermal fibroblast lines, CD10 and CD26 (Cappellesso-Fleury et al., 2010), were consistently higher on healthy than diseased tendon cells. We found no differential expression of CD9 in our studies (data not published). Significantly more healthy tendon cells cultured on electrospun fibres were $\mathrm{CD} 106^{\text {neg }} \mathrm{CD} 10^{+} \mathrm{CD} 26^{+}$than diseased cells.

If CD106 surface expression proves to be a reliable marker of undifferentiated mesenchymal cells, this result suggests that healthy tendons may harbour a greater proportion of mesenchymal stem cells than diseased tendons. The subsequent loss of CD106 from healthy tendon cells cultured on electrospun PDO fibres also suggests that this population could differentiate in response to biophysical cues. While the proportion of $\mathrm{CD} 10^{+}$and $\mathrm{CD} 26^{+}$healthy tendon cells did not change in response to electrospun fibres, significantly more healthy tendon cells cultured on electrospun fibres were $\mathrm{CD} 106^{\text {neg }} \mathrm{CD} 10^{+} \mathrm{CD} 26^{+}$ than diseased cells. In comparison, chronic diseased tendons may have exhausted their population of cells capable of further maturation. Those that remain may have adopted a more quiescent phenotype. Further study of cells from tendons at earlier disease stages may help identify when these changes occur, for example in response to prolonged inflammation or prior to tendon rupture. It would also be interesting to investigate whether a loss of surface CD106 correlates with increased expression of extracellular matrix proteins, a change in morphology or intracellular signalling.

Phenotyping of tendon cells, based on surface protein expression, is in the early stages of development and it is possible that these observations can be explained by the heterogeneity of the diseased versus the healthy tendon cell population. For example, this could account for the smaller population of $\mathrm{CD} 10^{+}$cells in diseased compared to healthy tendon cells, irrespective of their culture surface. In comparison to healthy tendons, it is likely that the cell population of diseased tendons changes significantly throughout the chronic pathological process. This may include an infiltration of acute and then chronic inflammatory cells, changes in tendon vascularity, the loss of undifferentiated cells, and phenotypic changes of fibroblasts, for example to a more chondroid phenotype (Dean et al., 2012; Matthews et al., 2006) This is an intriguing area of ongoing research and may highlight clusters of cell surface markers by which the various populations of diseased versus healthy tendon cells can be identified. Similarly, the ability to identify and isolate 'responsive' tenocytes using a collection of putative cell surface molecules is an important initial step in developing structural, pharmacological and cell based therapies.

This study compared the responses of human cells from two different tendons; healthy hamstring and diseased supraspinatus tendons (rotator cuff tears). We were unable to compare healthy and diseased cells from the same tendon due to practical and ethical restrictions. The healthy samples come from significantly younger patients raising the possibility that the observed differences are age, and not necessarily disease, related (Table 1). Healthy hamstring tendons are longer, more cord like than the flatter supraspinatus tendon and are subject to different cyclical loading. The in vitro phenotypic differences we observed could reflect differential behaviour of cells from different anatomical sites. The availability of healthy and diseased supraspinatus tendon, ideally from the same patient, will help address these issues as well as investigating further behavioural differences of tendon cells throughout the disease spectrum of tendinopathy. In addition, the extent to which in vitro cell culture affects the behaviour of cells remains an important limitation. Both diseased and healthy tendon explanted samples were initially cultured in media containing $50 \%$ bovine serum. This may have differentially affected diseased versus healthy cells. Investigating healthy and diseased cells immediately ex vivo, before further culture, will help reveal which characteristics of diseased cells can be overcome by putative therapies and which are hard wired in response to chronic tendinopathy.

By influencing and reacting to biophysical changes in the tissue, tendon cells could play a crucial role in maintaining tendon homeostasis in spite of mechanical attrition, acute injury or inflammatory insults. The increasing availability of synthetic scaffolds that mimic the extracellular matrix of tendons provides an opportunity to examine how these biophysical cues affect cell biology 
or promote resolution of inflammation to enable healing (Dakin et al., 2015). For the first time we have been able to show that cells from diseased, as well as healthy, tendons can be influenced by exposure to PDO electrospun fibres. Tendon cell interaction with the scaffold resulted in cell proliferation, marked changes in morphology, an increase in the ratio of type I to type III collagen mRNA expression and promotion of a differentiated cell phenotype $\left(\mathrm{CD} 106\right.$ negCD $\left.10^{+}\right)$. This work supports the continued development of absorbable electrospun scaffolds as a therapeutic strategy to improve diseased tendon repair.

\section{Conclusion}

Human cells from diseased supraspinatus tendons show phenotypic differences compared to healthy hamstring cells in terms of dynamic cell morphology, cell surface proteins and type I to type III collagen mRNA expression. This study cannot exclude the different tendon types as an explanation for these observations. Despite these phenotypic differences, electrospun PDO fibres were able to induce marked morphological changes and increase the proliferation of diseased tendon derived cells.

Future work may use similar in vitro outcome measures to inform the design of absorbable scaffolds in the hope that they can further modify the behaviour of diseased cells. Beyond their therapeutic possibilities, the development of absorbable, synthetic extracellular scaffolds provides a means to explore how cells respond to biophysical cues to help maintain tissue homeostasis.

\section{Acknowledgements}

National Institute for Health Research, UK, has funded this research project for help with GFP-LifeAct transfection of primary human fibroblasts.

\section{References}

Ahmed SA, Gogal RM, Jr., Walsh JE (1994) A new rapid and simple non-radioactive assay to monitor and determine the proliferation of lymphocytes: an alternative to $[3 \mathrm{H}]$ thymidine incorporation assay. J Immunol Methods 170: $211-224$.

Bashur CA, Shaffer RD, Dahlgren LA, Guelcher SA, Goldstein AS (2009) Effect of fiber diameter and alignment of electrospun polyurethane meshes on mesenchymal progenitor cells. Tissue Eng Part A 15: 2435-2445.

Bhowmick S, Scharnweber D, Koul V (2016) Cocultivation of keratinocyte-human mesenchymal stem cell (hMSC) on sericin loaded electrospun nanofibrous composite scaffold (cationic gelatin/hyaluronan/ chondroitin sulfate) stimulates epithelial differentiation in hMSCs: In vitro study. Biomaterials 88: 83-96.

Bishop J, Klepps S, Lo IK, Bird J, Gladstone JN, Flatow EL (2006) Cuff integrity after arthroscopic versus open rotator cuff repair: a prospective study. J Shoulder Elbow Surg 15: 290-299.
Cappellesso-Fleury S, Puissant-Lubrano B, Apoil PA, Titeux M, Winterton P, Casteilla L, Bourin P, Blancher A (2010) Human fibroblasts share immunosuppressive properties with bone marrow mesenchymal stem cells. J Clin Immunol.30: 607-619.

Chard MD, Hazleman R, Hazleman BL, King RH, Reiss BB (1991) Shoulder disorders in the elderly: a community survey. Arthritis Rheum 34: 766-769.

Chaurey V, Block F, Su YH, Chiang PC, Botchwey E, Chou CF, Swami NS (2012) Nanofiber size-dependent sensitivity of fibroblast directionality to the methodology for scaffold alignment. Acta Biomater 8: 3982-3990.

Codman EA, Akerson IB (1931) The pathology associated with rupture of the supraspinatus tendon. Ann Surg 93: 348-359.

Dakin SG, Martinez FO, Yapp C, Wells G, Oppermann U, Dean BJ, Smith RD, Wheway K, Watkins B, Roche L, Carr AJ (2015) Inflammation activation and resolution in human tendon disease. Sci Transl Med 7: 311ra173.

de Mos M, van El B, DeGroot J, Jahr H, van Schie HT, van Arkel ER, Tol H, Heijboer R, van Osch GJ, Verhaar JA (2007) Achilles tendinosis: changes in biochemical composition and collagen turnover rate. Am J Sports Med 35: $1549-1556$.

Dean BJ, Franklin SL, Carr AJ (2012) A systematic review of the histological and molecular changes in rotator cuff disease. Bone Joint Res 1: 158-166.

Dean BJ, Franklin SL, Murphy RJ, Javaid MK, Carr AJ (2014) Glucocorticoids induce specific ionchannel-mediated toxicity in human rotator cuff tendon: a mechanism underpinning the ultimately deleterious effect of steroid injection in tendinopathy? Br J Sports Med 48: 1620-1626.

Doshi J, Reneker D (1993) Electrospinning process and applications of electrospun fibres. Industry Applications Society Annual Meeting.

Fleischer S, Miller J, Hurowitz H, Shapira A, Dvir $T$ (2015) Effect of fiber diameter on the assembly of functional 3D cardiac patches. Nanotechnology 26: 291002.

Galatz LM, Ball CM, Teefey SA, Middleton WD, Yamaguchi K (2004) The outcome and repair integrity of completely arthroscopically repaired large and massive rotator cuff tears. J Bone Joint Surg Am 86-A: 219-224.

GBD 2013 DALYs and HALE Collaborators (2015) Global, regional, and national disability-adjusted life years (DALYs) for 306 diseases and injuries and healthy life expectancy (HALE) for 188 countries, 1990-2013: quantifying the epidemiological transition. Lancet 386: 2145-2191.

Gomes SR, Rodrigues G, Martins GG, Roberto MA, Mafra M, Henriques CM, Silva JC (2015) In vitro and in vivo evaluation of electrospun nanofibers of PCL, chitosan and gelatin: a comparative study. Mater Sci Eng C Mater Biol Appl 46: 348-358.

Hakimi O, Mouthuy PA, Zargar N, Lostis E, Morrey M, Carr A (2015) A layered electrospun and woven surgical scaffold to enhance endogenous tendon repair. Acta Biomater 26: 124-135.

Halfon S, Abramov N, Grinblat B, Ginis I (2011) Markers distinguishing mesenchymal stem cells from 
fibroblasts are downregulated with passaging. Stem Cells Dev 20: 53-66.

Ireland D, Harrall R, Curry V, Holloway G, Hackney R, Hazleman B, Riley G (2001) Multiple changes in gene expression in chronic human Achilles tendinopathy. Matrix Biol. 20: 159-169.

Kim DH, Han K, Gupta K, Kwon KW, Suh KY, Levchenko A (2009) Mechanosensitivity of fibroblast cell shape and movement to anisotropic substratum topography gradients. Biomaterials 30: 5433-5444.

Lam AJ, St-Pierre F, Gong Y, Marshall JD, Cranfill PJ, Baird MA, McKeown MR, Wiedenmann J, Davidson MW, Schnitzer MJ, Tsien RY, Lin MZ (2012) Improving FRET dynamic range with bright green and red fluorescent proteins. Nat Methods 9: 1005-1012.

Lee CH, Shin HJ, Cho IH, Kang YM, Kim IA, Park KD, Shin JW (2005) Nanofiber alignment and direction of mechanical strain affect the ECM production of human ACL fibroblast. Biomaterials 26: 1261-1270.

Liu F, Akiyama Y, Tai S, Maruyama K, Kawaguchi Y, Muramatsu K, Yamaguchi K (2008) Changes in the expression of CD106, osteogenic genes, and transcription factors involved in the osteogenic differentiation of human bone marrow mesenchymal stem cells. J Bone Miner Metab 26: $312-320$.

Matthews TJ, Hand GC, Rees JL, Athanasou NA, Carr AJ (2006) Pathology of the torn rotator cuff tendon. Reduction in potential for repair as tear size increases. $\mathrm{J}$ Bone Joint Surg Br. 88: 489-495.

Mohanty N, Gulati BR, Kumar R, Gera S, Kumar S, Kumar P, Yadav PS (2014) Phenotypical and functional characteristics of mesenchymal stem cells derived from equine umbilical cord blood. Cytotechnology 68: 795-807.

Schmittgen TD, Livak KJ (2008) Analyzing real-time PCR data by the comparative C(T) method. Nat Protoc 3: 1101-1108.

Shukunami C, Takimoto A, Oro M, Hiraki Y (2006) Scleraxis positively regulates the expression of tenomodulin, a differentiation marker of tenocytes. Dev Biol 298: 234-247.

Sill TJ, von Recum HA (2008) Electrospinning: applications in drug delivery and tissue engineering. Biomaterials 29: 1989-2006.

Simmons PJ, Masinovsky B, Longenecker BM, Berenson R, Torok-Storb B, Gallatin WM (1992) Vascular cell adhesion molecule-1 expressed by bone marrow stromal cells mediates the binding of hematopoietic progenitor cells. Blood 80: 388-395.

Smith RD, Carr A, Dakin SG, Snelling SJ, Yapp C, Hakimi O (2016) The response of tenocytes to commercial scaffolds used for rotator cuff repair. Eur Cell Mater 31: 107-118.

Sugaya H, Maeda K, Matsuki K, Moriishi J (2007) Repair integrity and functional outcome after arthroscopic double-row rotator cuff repair. A prospective outcome study. J Bone Joint Surg Am 89: 953-960.

Urwin M, Symmons D, Allison T, Brammah T, Busby H, Roxby M, Simmons A, Williams G (1998) Estimating the burden of musculoskeletal disorders in the community: the comparative prevalence of symptoms at different anatomical sites, and the relation to social deprivation. Ann Rheum Dis 57: 649-655.

Voytik-Harbin SL, Brightman AO, Waisner B, Lamar $\mathrm{CH}$, Badylak SF (1998) Application and evaluation of the alamarBlue assay for cell growth and survival of fibroblasts. In Vitro Cell Dev Biol Anim 34: 239-246.

Yao L, Bestwick CS, Bestwick LA, Maffulli N, Aspden RM (2006) Phenotypic drift in human tenocyte culture. Tissue Eng 12: 1843-1849.

\section{Discussion with reviewers}

Reviewer II: Do you plan to repeat the experiments with tendons from animal models for the direct comparison of diseases and healthy RC tendon?

Authors: The use of two different tendon types from different patient groups is an important limitation of this work and we appreciate the benefits of an appropriate model. It is likely that ovine models would be required if future work is limited to tendinopathy of the rotator cuff. Rodent models could be used if the research is extended to include tendinopathy of the Achilles or patella tendons.

An alternative approach is to refine the outcome measures such that fewer cells from smaller samples can be used. When combined with improvements in percutaneous sampling techniques with very low morbidity, it might then be possible to compare healthy and diseased samples from the same tendon type and/or from the same patient. Possible sources include the supraspinatus tendons and the Achilles tendon.

Reviewer III: The authors are invited to speculate on possible reasons or mechanisms why diseased tenocytes have a later response to the electrospun fibres compared to healthy tenocytes.

Authors: Three possible explanations include:

Preferential selection of highly adherent diseased cells during the live cell imaging assay which are not representative of the diseased cell population as a whole. There may be a more dynamic group of cells which fail to adhere to the electrospun fibres under the live cell imaging conditions.

Greater heterogeneity of diseased cells as discussed, including a group that do not respond to the same biophysical cues. This could include infiltration of cells as part of the chronic disease process. Although a bimodal distribution of diseased cell shape on electrospun fibres was not seen in this study.

Prolonged tendon disease state may alter the phenotype of resident cells away from migration, elongation, proliferation and normal matrix production towards behaviour more suited to salvaging tendon integrity with fibrosis and calcification.

Reviewer III: The authors suggest that the PDO nanofibres could attract endogenous tenocytes into the repair site and support proliferation in clinical use. Should proliferation be a key part of a bioactive scaffold and is proliferation of 
tenocytes alone sufficient to make a more functional repair and reduce current high tendon failure rates?

Authors: We would argue that the ability of these scaffolds to support the growth and survival of cells is a more important initial property than greatly increasing the rate of proliferation. At present it is not clear that proliferation is a requisite for improved tendon healing. We used cell proliferation as evidence that the scaffolds support cell survival.

The migration of responsive cells to the repair site, their ability to conform to the scaffold, to span the defect and to produce reparative extracellular matrix in a structured manner may prove to be more important parameters clinically. Similarly, these attributes need not be dependent on proliferation if there is sufficient recruitment of cells.

Reviewer IV: Do you observe differences (e.g. timing, number of cells, adhesion properties, ...) during the explant outgrowth period between healthy and diseased tendon samples? If so, how would those differences influence the subsequent behaviour of cells in your assays?

Authors: It is possible to see a difference when explanting hamstring versus diseased rotator cuff tendons. The healthy cells demonstrate better tissue adherence for a prolonged time and result in a better explant outgrowth. Normally, hamstring samples adhere more rapidly to the plate and a sufficient number of cells migrate out of the explant after about 2 weeks. The diseased rotator cuff tendon cells are less adherent and migrate over a period of up to 4 weeks. However, from Passage 1 both type of cells have similar growth and proliferative rates.

The slower rate of cell migration from explanted diseased tendons may be mirrored by the slower change in morphology demonstrated in response to electrospun fibres. In addition, any impairment in adhesion to electrospun fibres may result in the selection of a smaller proportion of of diseased cells during the live cell imaging assays.

Finally, prolonged tendon disease state may alter the phenotype of resident cells away from migration, elongation, proliferation and normal matrix production towards behaviour more suited to salvaging tendon integrity with fibrosis and calcification.

Reviewer IV: Does the cell growth on electrospun PDO fibres allow assessment of collagen production, secretion and assembly? If so, would you expect any difference between healthy and diseased tenocytes.

Authors: This is a very interesting question and one that we had planned to investigate using dual fluorescent live cell microscopy of LifeAct-GFP and collagen fluorescent probes. We would be particularly interested to follow the time frame of extracellular matrix protein production during the change in morphology.

Reviewer IV: As you mentioned in the discussion, the identification and isolation of "responsive" tenocytes is important to develop therapies. Would you consider the combined assessment of morphology (x/y ratio) and cell surface markers expression (e.g CD106, CD10, CD26) as a relevant initial step?

Authors: Yes, this is a very good idea and one that we would be keen to pursue. A crucial initial step is to use flow cytometry to develop a panel of cell surface markers by which tendon cells can be identified. Thereafter, one could begin to investigate a correlation with fixed immunofluorescence before attempting in situ RNA staining for CD106, CD10 in the live imaging settings as suggested.

Editor's note: The Scientific Editor responsible for this paper was Juerg Gasser. 